\title{
LIGAÇÕES PERIGOSAS: REFLEXÃO SOBRE OS PORTÕES DO CENTRAL PARK DE NOVA IORQUE
}

\section{MEDEIROS, EUGÊNIO MARIANO FONSECA}

Professor Doutor do Departamento de Arquitetura e Urbanismo da Universidade Federal do Rio Grande do Norte email: euros60@gmail.com

\section{RESUMO}

Inicialmente parte de uma tese de Doutorado, este artigo reflete sobre o significado dos portões do Central Park de Nova lorque e suas relações com a evolução histórica da área onde se situa. Foram levadas em consideração tanto as modificações surgidas dentro do parque como aquelas que ocorreram e continuam a ocorrer ao seu redor, quer financeiras quer políticas e/ou administrativas. Com base nesse contexto geral, procuramos situar o primeiro parque urbano dos Estados Unidos, criado para atender à população de uma cidade que crescia em ritmo acelerado, e planejado de modo democrático, no sentido mais latu sensu da palavra. Enfocamos os pontos de contato entre o parque e a cidade, analisando a natureza simbólica dos seus portões, propostos por Olmsted como homenagem às classes trabalhadoras que construíram Nova lorque, transformando-a numa metrópole sofisticada. Os nomes destes portões, sugeridos pelo Conselho de Comissários do parque, evocaram tanto as tarefas braçais quanto intelectuais sem deixar de lado o gênero. Hoje, 160 anos após sua fundação, num século turbulento, cheio de maquinações financeiras, crises políticas e culto à Personalidade, como se encontram estes portões que homenageiam os mais humildes?

PALAVRAS-CHAVE: Central Park; portões; projeto urbano; projeto paisagístico.

\section{RESUMEN}

Originalmente parte de una tesis de Doctorado, este artículo reflexiona sobre el significado simbólico de los portones del Central Park de Nueva York y sus relaciones con el entorno dentro la evolución histórica en el área en que se ubica. Fueran tomadas en consideración tanto las modificaciones surgidas dentro del parque, como aquellas que ocurrieran y continúan a ocurrir al su rededor, sea esta financiera, política y/o administrativa. Con base en este contexto general, intentamos posicionar el futuro del primero grande parque urbano de los Estados Unidos, creado para atender al pueblo de una ciudad que crecía en ritmo acelerado, y planeado de manera democrática en el más latu sensu de la palabra. Enfocamos los puntos de contacto entre el parque y la ciudad, analizando la naturaleza simbólica de sus portones que han sido propuestos por Olmsted como homenaje a las clases obreras que construyeron Nueva York, convirtiéndola en una metrópoli cosmopolita y sofisticada. Los nombres sugeridos por el Consejo de Comisarios del parque evocaron tanto las tareas manuales como intelectuales sin olvidar el género. ¿Hoy, 160 años después de su fundación, en un siglo turbulento, lleno de maquinaciones financieras, crises políticas y culto a la Personalidad, como se encuentran estos portones que homenajean los más humildes?

PALABRAS CLAVES: Central Park; portones; diseño urbano; diseño paisajístico.

\section{ABSTRACT}

Originally as part of a PhD thesis, this paper reflects upon the symbolic meanings of New York Central Park gates and their relations with the surroundings, within the historic evolution in the area where they stand. We considered both the changes that arose inside the park as those that took e still take place around it, whether financial, political and/or administrative. Considering the general context we tried to place the future of the United States first great park, created specifically to fulfill the overall population needs, of a city that was growing in fast pace and planned in a democratic way, in the word most latu sensu. We focused the contact points between the park and the city, analyzing the symbolic nature of its gates, proposed by Olmsted as a tribute to the working classes that built New York, turning it into a sophisticated and cosmopolitan metropolis. The names suggested by the Park Board of Commissioners evoked as much the manual as intellectual labors, without forgetting the genre. Today, 160 after its foundation, in a turbulent and full of financial schemes century, political crises and Personality cult, how stand these gates that commemorate the more humble?

KEYWORDS: Central Park; gates; urban design; landscape architecture.

\section{INTRODUÇÃO}

No início do século XIX, teve início o processo de expansão urbana da cidade de Nova lorque, que perduraria durante todo o século. Começado de maneira aleatória, este processo levou a municipalidade a rever os planos de seu crescimento, o que aconteceu através do Plano de 1811, elaborado pelo Conselho Comunitário da cidade a fim de possibilitar um desenvolvimento ordeiro, inclusive quanto à venda e ocupação da área. O plano previa que a cidade recebesse uma grade de parcelamento ortogonal em lotes iguais, que é visível até hoje, apesar dos ataques à sua lógica racional.

Inserido nesta grade surgiu o Central Parque de Nova lorque (CP - Figuras 1 e 2). Um dos elementos mais citados pelos autores como justificativa para sua criação foi o extraordinário aumento da população da cidade em meados do século XIX, dando origem ao que contemporaneamente denominamos 'crowding'. 
Aqui consideramos crowding (apinhamento ou aglomeração) "a resposta psicológica das pessoas à densidade, isto é, a sensação de estar sendo comprimida, de estar tendo falta de privacidade, de estar tendo um aumento de interações indesejadas ou angústia psicológica" (GREY, 2001, p.8).

Devido a uma série de ocorrências que influíram em seu futuro, a população novaiorquina, que era de 70.000 habitantes em 1800, em meados de 1850 saltou para meio milhão (SLAVICEK, 2009). O apinhamento vivenciado era tal que "em alguns lugares 100.000 pessoas eram espremidas em $2.600 \mathrm{~m}^{2 "}$ (MARTIN, 2011, p.126), o equivalente a 3,87 pessoas $/ \mathrm{m}^{2}$. Frente a esta realidade, a criação de um parque se delineou como o mínimo que poderia ser feito para amenizar a excessiva densidade física e social.

Figura 1: Mapa topográfico de Egbert Viele mostrando a área do CP, planta datada de 1872 (sem escala)

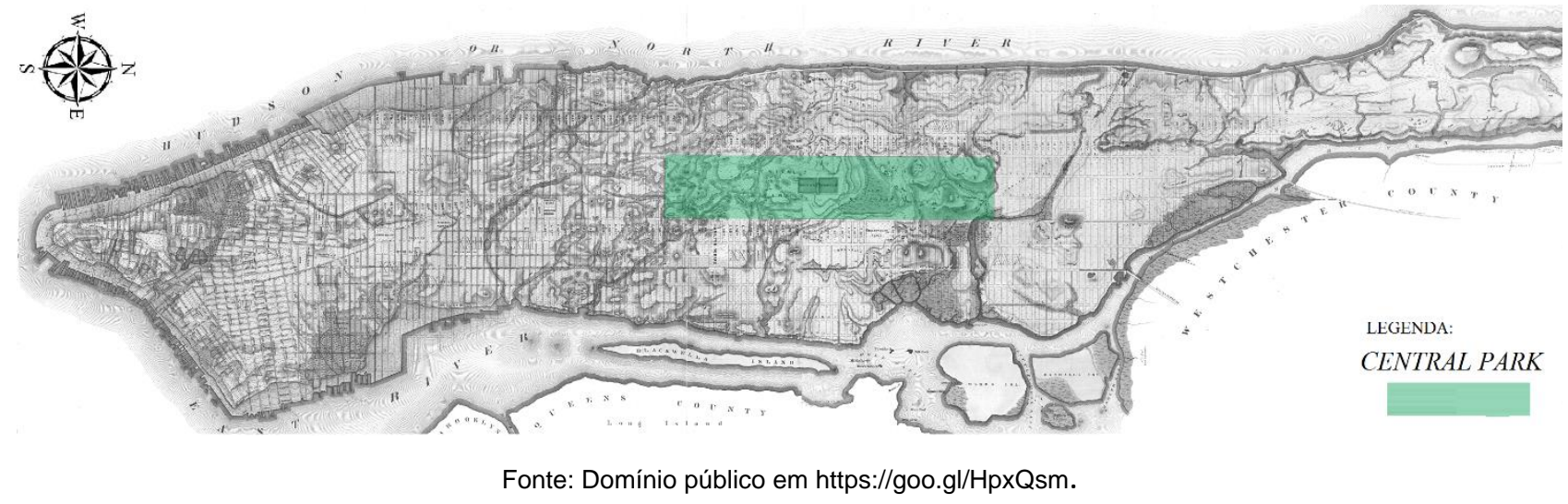

Figura 2: Planta do projeto original do CP, elaborada por Olmsted e C. Vaux (1862) Área ocupada: $400 \mathrm{ft}: 1 \mathrm{inch}$ (aproximadamente $1 \mathrm{~km}: 4 \mathrm{~km}$ ).

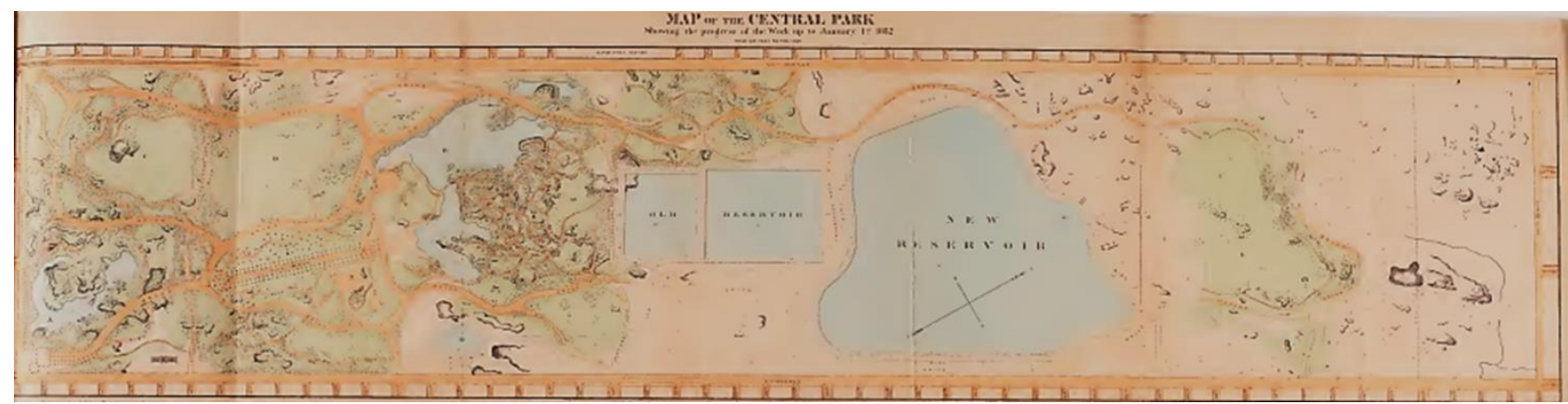

Fonte: Green, Russell e Stebbins (1870).

Complementarmente, Nova lorque desejava um parque que rivalizasse com as grandes capitais europeias, às quais gostaria de se igualar (ou mesmo suplantar). No entanto, para seu criador, o humanista, jornalista, paisagista, crítico social e administrador público Fredrick Law Olmsted (1822-1903), o parque não apenas serviria como local conveniente à descarga das aflições da população geradas pelo crowding, mas também, e principalmente, deveria tornar-se ponto de encontro e mistura saudável entre as diversas classes sociais, possibilitando que pessoas com diferentes origens convivessem e aprendessem umas com a outras (OLMSTEAD, 1870).

Em seu prefácio para o livro "Central Park: An American Masterpiece" (de Sara Cedar Miller, 2003), Keneth Miller comenta que o CP não é o mais antigo, maior ou mais bonito espaço livre público dos Estados Unidos ou do mundo, no entanto, ele o considera o mais importante dos Estados Unidos, por ter sido "...o primeiro grande espaço livre destinado intencionalmente para o cidadão comum numa cidade próspera e ambiciosa" (MILLER, 2003, p.7).

Para definir o parque como "público", foram tomadas muitas medidas que provocaram antagonismos e críticas, por exemplo: não cobrar entrada, já que, sendo público, o parque seria mantido pela arrecadação da municipalidade; ter nome genérico, sem homenagear ninguém, para não criar ligações antidemocráticas; evitar muros de confinamento (OLMSTED, VAUX, 1858).

A ideia de portões com nomes que homenageassem as categorias de trabalhadores que contribuíram para o crescimento e existência de Nova lorque partiu do Conselho de Comissários do Central Park, e deve sua existência à determinação de Andrew Haswell Green, embora esta autoria seja atribuída a Olmsted. Os 
portões ainda existem e ainda ostentam os nomes iniciais, apesar das reviravoltas que o parque tem sofrido ao longo de sua tribulada existência.

Os apontamentos iniciais para este artigo são parte de uma tese de doutorado defendida no PPGAU/UFRN (MEDEIROS, 2014), cujo objetivo foi compreender o Central Park como ambiente restaurador no contexto da cidade de Nova lorque, usando como fonte de informações o cinema. Naquele trabalho, um capítulo inicial contextualizou o local em estudo, comentando a elaboração do projeto que o originou e a consolidação do parque como importante espaço da cidade, e contendo um tópico dedicado aos seus portões. Alçando esse assunto à condição de foco, este artigo comenta o surgimento e papel das ligações do CP com a cidade, dividindo-se em dois itens: o contexto e os portões.

\section{PERIGO (OU O CONTEXTO E SEUS ELEMENTOS)}

Em 1728, Choderlos de Laclos escreveu o romance Ligações Perigosas (Les Liaisons Dangereuses), cuja trama é tecida por intermédio de copiosa correspondência, trocadas entre personagens vis e ricas do grand monde da época. Embora o foco do livro sejam as delícias da rarefeita atmosfera da aristocracia da França pré-revolucionária, parte da descritiva percorre os corredores sombrios e ocultos do coração e da corrupção no tacanho mundo do poder. Cem anos depois, intrigas e acobertamentos teceram uma malha semelhante no entorno do Central Park (CP): intrigas políticas, decepções aristocráticas e uma tremenda força de vontade e determinação administrativa de seus criadores, dentre os quais destacamos Frederick Law Olmsted (FLO), ou simplesmente Olmsted.

Embora fosse descendente direto dos Pais Fundadores dos Estados Unidos, Olmsted cresceu e viveu de forma autônoma crendo, como Thoreau, na independência do indivíduo em relação ao Estado e em sua dissolução no coletivo. Nem comunista, nem socialista, porém comunitário (ou comunitarista), usou de uma incansável capacidade investigativa e prolixa descritiva para denunciar e inflamar o Abolicionismo, do qual participou ativamente como libelista e colaborador, mesmo enquanto construía o Central Park.

Para Rosenzweig e Blackmar (1992, p.18), o Central Park emergiu "de uma complexa mistura de motivações - fazer dinheiro, exibir a cultura da cidade, erguer o pobre, refinar o rico, aumentar os lucros comerciais, inibir a expansão do livre-comércio, melhorar a saúde pública, obter favores políticos e fornecer empregos"1. Considerada um dos $\mathrm{m}^{2}$ mais caros do mundo, a área de entorno do Central Park é hoje considerada a joia da coroa no caso de Nova lorque, já que concentra grande parte dos museus mais importantes dos Estados Unidos, assim como edifícios icônicos do início da arquitetura vertical do início do século XX. O Fifth Avenue Bank of New York (1915) publicou uma brochura em que relata a história da mais honorável via americana até então, "uma das ruas mais famosas do mundo", equiparando-a a Bond Street em Londres, ao Ringstrasse em Viena e a Rue De La Paix em Paris.

A importância da Quinta Avenida surgiu a partir da implantação do CP, e a sua valorização imobiliária e que, segundo Rosenzweig e Blackmar (1992), Ihe valeu a alcunha de Millionaire's Row (Fileira de Milionários), pois aí viviam os Vanderbilt, Fricks, Rockfellers, Morgans e outras celebridades das finanças, que fizeram questão absoluta de competir pelo imóvel mais faustoso e imponente. $O$ resultado foi uma coleção de arquiteturas tão extravagantes e díspares no gênero e na aparência da qual, apenas algumas das grandes mansões, como a Frick e a Stuyvesant, sobreviveram às pressões imobiliárias do século XX, sendo transformadas em museus.

Este espaço de entorno terminou por se auto organizar, marcando o conjunto de suas edificações de maneira evidente. A Quinta Avenida ficou com grande parte dos museus, quiçá, devido à presença do MET (Metropolitan Museum of Art) e da Central Park West, com grandes condomínios de luxo, alguns dos quais foram tão incorporados à paisagem urbana que se tornaram icônicos, como o edifício Dakota (onde John Lennon foi assassinado e o Bebê de Rosemary foi filmado) e as torres do San Remo (Figura 3). 
Figura 3: Edifício Dakota (à esquerda) e Torres San Remo (à direita)
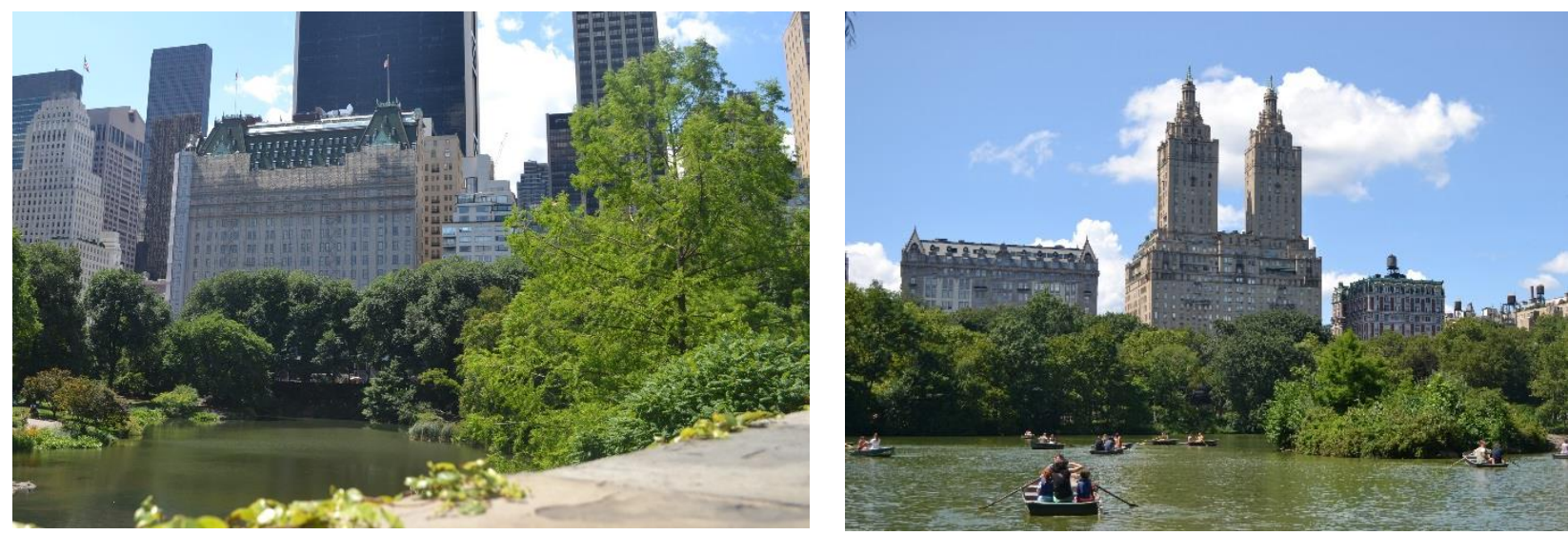

Fonte: Fotos cedidas por Indra Rodies (2014).

Assim, começando pela Quinta Avenida a partir da Rua 110, temos (conforme Figura 4) o Charles Dana Discovery Center, que funciona como um dos principais centros de visitas do Central Park; o Museo Del Barrio, dedicado as artes dos países latino-americanos; o Museum of the City of New York, dedicado à história da cidade e contando com o maior acervo de fotos e documentos da mesma; o Jewish Museum; o Cooper-Hewitt Museum, uma ala da Smithsonian Institution dedicada ao Design; o Guggenheim Museum albergando a coleção de arte moderna e contemporânea; a Frick Collection dedicada ao mobiliário e, obviamente, o MET. A Central Park West, ou Oitava Avenida, manteve grande parte de suas edificações, onde se encontra o metro quadrado mais caro da cidade.

Figura 4: Mapa esquemático dos arredores do CP indicando principais edifícios dos arredores

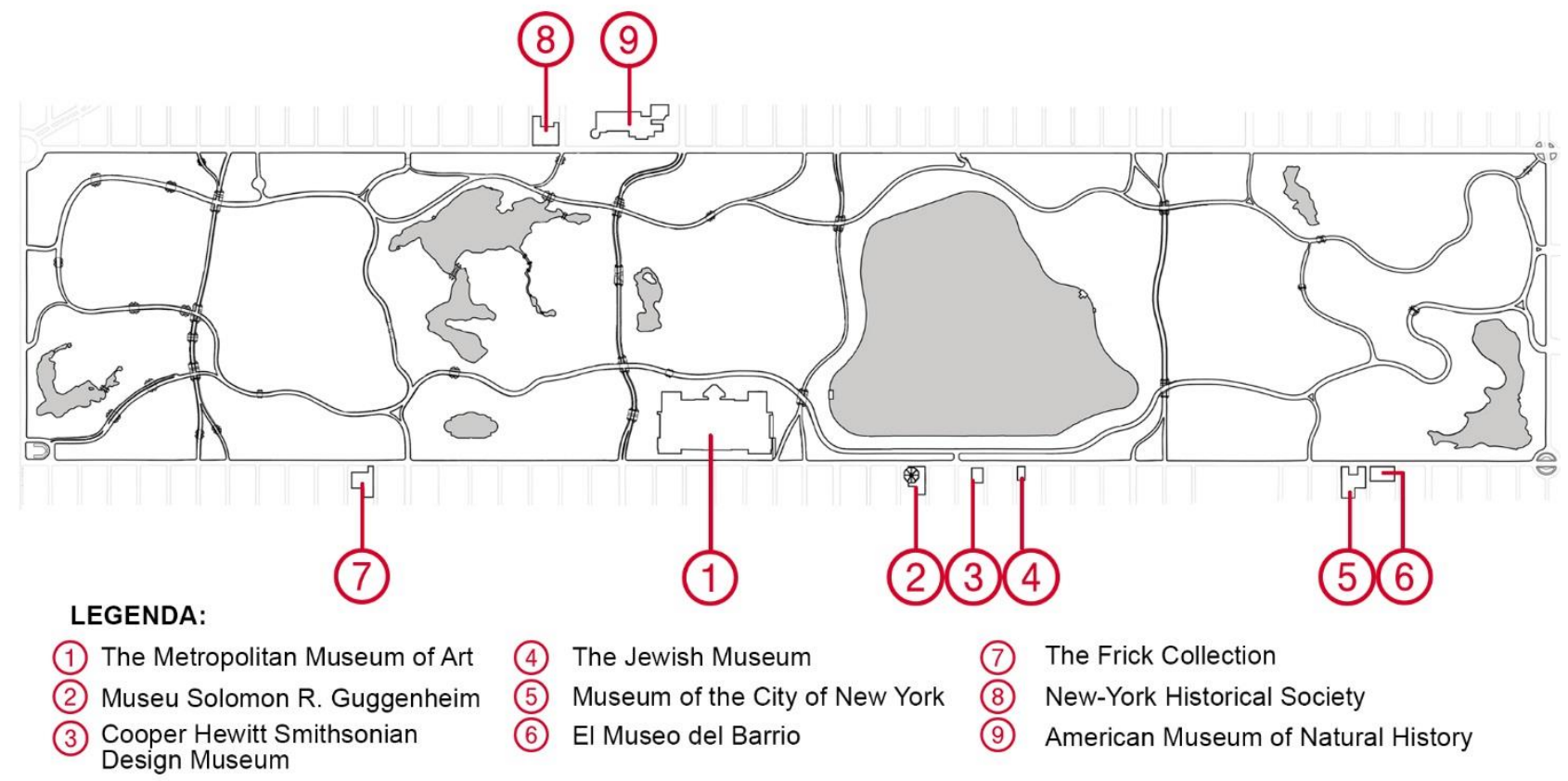

Fonte: O autor, mapa retrabalhado por Felipe S. Oliveira.

\section{AS LIGAÇÕES (OU OS PORTÕES)}

Um detalhe aparentemente irrisório, mas de relevante importância para compreender a idealização do CP, é o modo como FLO estabeleceu suas relações com o entorno. Ao invés de cerca, muro ou gradeado, inicialmente proposto pelos potentados que moravam ao lado e que marcariam o CP como propriedade privada, o projeto optou por uma mureta baixa (servindo como delimitador), e entradas bem marcadas, dispostas a intervalos regulares. Ironicamente, estas entradas, financiadas pelos ricos que moravam na Millionaire's Row, homenageariam o cidadão comum. 
Para se chegar aos portões (gates) é preciso primeiro entender o processo de gerenciamento das entradas, o qual, embora tenha gerado muita polemica e controvérsia durante a execução, ainda assim é emblemático. Inicialmente foram propostos quatro portões monumentais que deram origem as atuais quatro rótulas (rotatórias): Columbus' Circle, Great Army Plaza, Duke Ellington e Frederick Douglas.

Pelo lado sul, encontramos na quina da Rua 59 com Avenidas 8 (Central Park West) a Columbus's Circle (Rótula de Colombo) a qual deveria adicionar um tipo de grandiosidade que competisse com a Place de La Concorde de Paris (MILLER, 2003), embora atualmente exponha um Monumento ao Maine. Entre a Rua 59 e Quinta Avenida (Fifth Avenue), encontra-se a Grand Army Plaza erguida com a justificativa de homenagear o Exército da União (da Guerra Civil), e ostentando o Monumento ao General Sherman.

Pelo lado norte, confinando com o Harlem, encontramos, entre as avenidas 8 e 5, pela Rua 110 mais duas rótulas, as quais homenageiam respectivamente dois grandes afrodescendentes norte-americanos: Fredrick Douglas, advogado, escritor e ativista da luta antiescravista, na quina da Av. 8 com Rua 110; e Duke Ellington em substituição a Frawley, na quina da Quinta Avenida com a Rua 110 (Figura 5).

Figura 5: Esquema gráfico dos quatro portões monumentais do CP (sem escala)

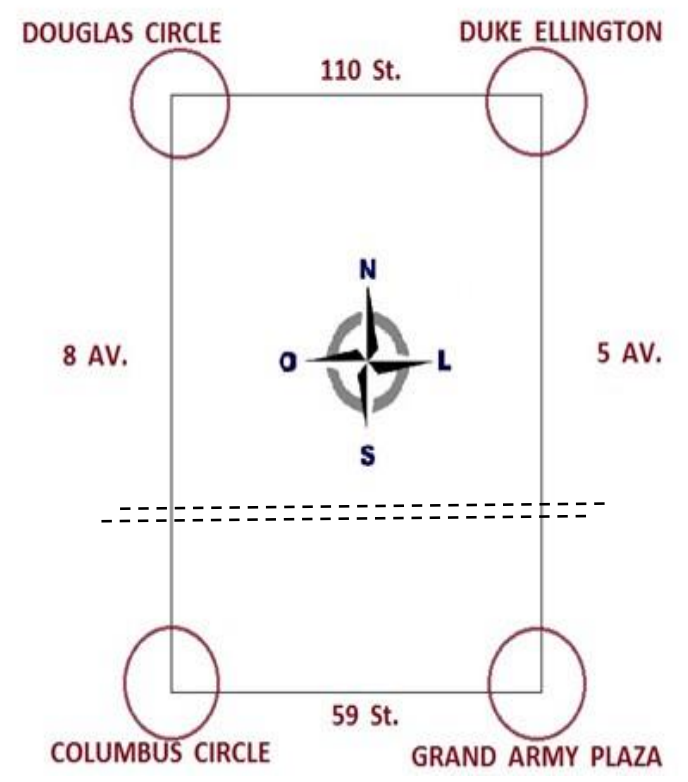

Fonte: O autor, com base nas imagens do Google Earth.

A Columbus Circle, erigida em 1892 e concluída em 1905, era parte da visão que Olmsted tinha da principal entrada pela Oitava Av. para comemorar os 400 anos da chegada de Colombo às Américas. Consiste numa estátua de Colombo no topo de uma coluna rostral de $21 \mathrm{~m}$. e decorada com relevos em bronze representando as naus Santa Maria, Pinta e Niña, embora se pareçam mais com galeras romanas que caravelas.

A Grand Army Plaza, cujo nome deriva do Grand Army of Potomac, é a única que é parte oficial do paisagismo do $\mathrm{CP}$, além de entrada principal para carruagens. Consiste, na verdade, em duas praças semicirculares devido a uma bissecção da 59 St. com desenho inspirado na Praça da Concórdia de Paris. Na parte sul, defronte o Hotel Plaza está a Fonte Pulitzer, coroada com a estátua de Pomona, deusa da Abundância, e na parte norte a estátua equestre dourada do General William Tecumseh Sherman, herói da Guerra Civil. Proposta em 1898, a praça foi concluída em 1916 e nomeada com tal em 1923.

A Frederick Douglass Circle, embora projetada em 1950 só foi concluída em 2010. A rótula não aparece nos mapas do século XIX, sendo representado apenas como um grande cruzamento. A praça para pedestres consiste de uma estátua em bronze dourado de Douglass e um padrão de pavimentação colorido alusivo as colchas e mantas afro-americanas. Houve um plano diretor dos anos 1970 que jamais saiu da prancheta.

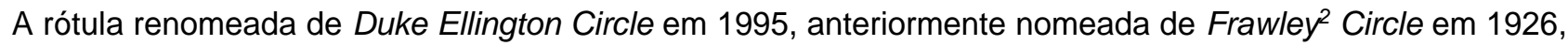
faz homenagem ao músico com uma estátua do mesmo e as nove musas sustentando um grande piano no centro do anfiteatro que compõe a rótula. O conjunto kitsch que homenageia $D$. Ellington só foi entregue em 1997. 
A proposta de Hunt ${ }^{3}$ para o portão do Grand Army Plaza, provocou ataques furiosos por parte de Vaux ${ }^{4}$, que após uma áspera contenda em defesa do parque, terminou encontrando um meio termo para a inserção deste. Pela defesa de Hunt, percebemos que o grandeur que cercava o parque, não era exclusividade do Millionaire's Row.

Os vários desenhos para os diversos portões, conforme veremos, são todos de um caráter monumental, e foram combinados de modo a satisfazer os grandes requisitos de efeito, largura, altura e simplicidade; com qualquer ornamento espalhafatoso sendo cuidadosamente evitado. Se forem executados com bom gosto e habilidade, poderemos ansiosamente aguardar em ter uma fachada deste tipo, se assim pudermos chamá-la, em nosso grande parque de recreação como nenhuma cidade no mundo possa se gabar. Existem poucos exemplos de tais entradas no exterior dignas de avaliação, salvo o Bois de Boulogne, cuja entrada pode-se adequadamente ser dita ser o Arc de L'Etoile, no início do Champs Elisées que marca a saída da cidade para as amplas avenidas que levam ao Bois (HUNT, 1866, p.9).

Os portões, ao contrário, seguiram à risca a recomendação da "reforma social" de FLO, homenageando os segmentos sociais/existenciais que trabalharam no parque ou foram importantes para ele. Para Miller, os nomes nos portões "tinham o significado, no nível mais básico, de fornecer ao visitante um meio simples e objetivo de promover um ponto de encontro" além de serem um "(...) sermão em pedra que faz proselitismo de importantes valores culturais da Nova lorque de meados do século XIX” (MILLER, 2003, p. 17).

Green $^{5}$, em seu Fifth Annual Report (1862), relatou prolixamente como a Comissão chegou aos nomes dados aos portões do parque, alicerçando sua argumentação tanto na história da evolução do sentido de 'portão', quanto numa longa digressão sobre o significado das profissões e o status daqueles que trabalharam na construção de Nova lorque e, particularmente no Central Park, como exemplificado no texto:

Tomemos, primeiramente, aquela porção da população cuja esfera de utilidade é o trabalho manual. Essa grande e importante classe ao contribuir para a prosperidade da comunidade com todo o trabalho duro, positivo e tangível que é feito, merece, ao entrar no Parque, um reconhecimento respeitoso e caloroso. Ela deve, contudo, mal se identificar por termos tais como "operário" ou "mecânico", pois todo operário pode trazer alguma experiência ou discernimento ao seu trabalho, e todo mecânico pode mostrar algum grau de gosto e inteligência no exercício de sua arte: a palavra "Artesão", por outro lado, parece apresentar a ideia inteira em seu aspecto mais compreensível e desejável sendo, talvez, o título característico que pode ser usado (GREEN, 1862, p. 128-129) ${ }^{6}$.

Partindo desses parâmetros, no contexto geral os nomes não discriminaram ninguém especificamente, e sim grandes categorias de pessoas. A justificativa de FLO frente ao Conselho de Comissários do parque teve o sentido de homenagear todos aqueles que contribuíram para a construção e engrandecimento da cidade de Nova lorque. As profissões e categorias selecionadas faziam referência direta aos tipos genéricos e universais no século XIX.

Originalmente eram dezoito (18) portões (aqui citados em ordem alfabética): (Gate of) All Saints, Artizan, Artist, Boys, Children, Cultivator Engineer, Explorer, Foreigner, Girls, Inventor, Hunter, Mariner, Merchant, Miner, Scholar, Warrior, Fisherman, Women e Woodman. Estes nomes foram corrigidos ao longo do tempo, passado a ser: All Saints, Artisans', Artists', Boys', Children's, Engineers', Farmers', Girls', Hunters', Mariners', Merchants', Miners', Pioneers', Scholars', Strangers', Warriors', Women's e Woodmen's. Assim, o Cultivator (arcaísmo para Agricultor) se transformou em Farmer (Fazendeiro ou Agricultor) e o Foreigner (Forasteiro ou Estrangeiro) virado Stranger (Estranho ou Estrangeiro). O Explorer e Inventor jamais foram utilizados. Também deve-se notar que os nomes estão referenciados no plural e não no singular, sendo acrescidos do possessivo ('s). Logo, embora coloquialmente os portões sejam citados como estando no singular, a grande maioria deles está registrada com elementos no plural, o que amplia seu escopo de referência à categoria designada.

A parte defronte ao Harlem - bairro (neighborhood) tradicionalmente associado à população afro-americana e pobre - inicialmente não fazia nenhuma referência ao entorno. As modificações foram feitas posteriormente à administração de Green e Olmsted, conforme indicado anteriormente.

Verifica-se, ainda, que alguns dos portões tiveram seu nome trocado durante a gerência de Roberto Moses, nomeado por Fiorello LaGuardia então recém-eleito prefeito da cidade de Nova lorque, como Comissário do Departamento de Parques em 1934 (SLAVICEK, 2009). A crónica da época mostra a amplitude do cargo, comentando que Moses não foi indicado apenas como

(...) comissário de parques de toda a cidade, nem aquela função só iria se expandir para incluir poder sobre os caminhos nos parques, nem Moses iria apenas ter controle sobre as duas 'autoridades' com poder para construir pontes e estradas locais, ele também teria 
permissão para reter seus quatro diferentes empregos estaduais relacionados a parques e estradas (ROSENZWEIG, BLACKMAR, 1998, p. 448)

Portanto, como a confiança de LaGuardia em Moses era ilimitada, ele tinha plenos poderes para resolver qualquer assunto relativo à parques e estradas. Em 1934, Moses removeu os sem-teto do parque e instalou - Great Lawn e seus equipamentos esportivos de maneira a dar à cidade o que a cidade queria, sem ofender excessivamente o Greensward Plan.

Segundo Slavicek (2009), sua gestão incluiu 'melhorias' como a inserção de muitas quadras de esporte, o atual zoo, a construção do Tavern-on-the-Green, o Rinque de Patinação Wollman, tendo desagradado consideravelmente aos 'Olmstedianos', com a demolição do Abrigo Rústico Kinderberg (Kinderberg Shelter), do elegante Marble Arch próximo ao Mall, e de várias estruturas projetadas por Vaux. Uma boa demonstração da crítica da atuação de Moses pode ser encontrada em Lewis Munford, quando em 1951, denunciou no The New Yorker que Moses 'estava refazendo o Central Parque' (GARCÍA-POSADA, 2007).

Outro acréscimo de Moses, alheio às prerrogativas do Greensward, foi a demolição das estufas por serem muito dispendiosas; em seu lugar foi criado um espaço com jardins formais europeus (inglês, francês e italiano), dando origem ao atual Conservatory. Moses também mudou o nome do Portão das Crianças para Portão dos Inventores (P14), adicionando uma nova entrada ao lado do Zoo, e para aí transferindo o Portão das Crianças (P14). O Portão de Todos os Santos (All Saint's Gate) também é conhecido como Portão do Profeta (Prophet's Gate), embora esteja marcado como Todos os Santos (P03).

Por sua vez, o portão de entrada (P19) na 105 St. Leste, uma peça que já foi a entrada de carros do enorme château de Cornelius II Vendervilt na Quinta Avenida (WARBURG, 2016), foi doado ao parque por sua filha Gertrude em 1939 (WALDMAN, 2012). Estes portões já haviam estado na entrada do playground ao lado do MET até seu fechamento em 1970 devido ampliações no museu, sendo posteriormente transferido para o atual lugar.

No esquema da Figura 6 são apresentadas as atuais localizações e os nomes atuais dos portões, com indicação das áreas do parque em que respectivamente se encontram, sendo: cinza para Sul e Norte; vermelho para Oeste; amarelo para Leste; roxo para as rótulas; verde para as interpolações recentes; azul a única referência ao Millionaire's Row.

No blog Ephemeral New York, de Esther Crain (2010), existem muitas matérias dedicadas ao CP e, obviamente, debates de leitores discutindo e argumentando determinados fatos. No blog, o artigo Who Named the Gates of Central Park (Quem nomeou os portões do Central Park) discute se Olmsted deu ou não nome aos portões, argumentando que os três principais membros do Conselho do Central Park (H.G. Stebbins, C.H. Russell, and Andrew H. Green) criaram os nomes, tendo como base a ideia de Olmsted de usar os portões para homenagear as pessoas que ergueram Nova lorque. A discussão faz referência à autoria encontrada na página 132 do Relatório Anual do Central Park de 1861.

Outra cita atribuída à Olmsted em relação aos nomes dados aos portões do CP estaria no Relatório Anual do Conselho Administrativo do Central Park de 1866, conforme comentado no Ephemeral New York (CRAIN, 2010):

A cidade, embora metropolitana no papel, é cosmopolita em suas associações e simpatias, e sempre disponível para ir além de uma cortês acolhida a todos 'Desconhecidos' ou 'Estrangeiros' pacificamente dispostos, que possam ser levados por inclinação ou negócios a passar seu tempo dentro de suas fronteiras; sendo essa acolhida dada, contudo, não apenas por cortesia, mas como reconhecimento do fato que é de grande importância tanto para os interesses gerais quanto particulares de toda a nação, que suas cidades deveriam ser visitadas e suas instituições estudadas e compreendidas pelos inteligente e diligentes viajantes de outros países, pois só assim poderão indignos preconceitos serem removidos e as estimativas incorretas serem corrigidas (OLMSTEAD, 1866, apud CRAIN, 2010, s/p). ${ }^{8}$ 
Figura 6: Quadro com localização e nomes dos portões do CP (sem escala)

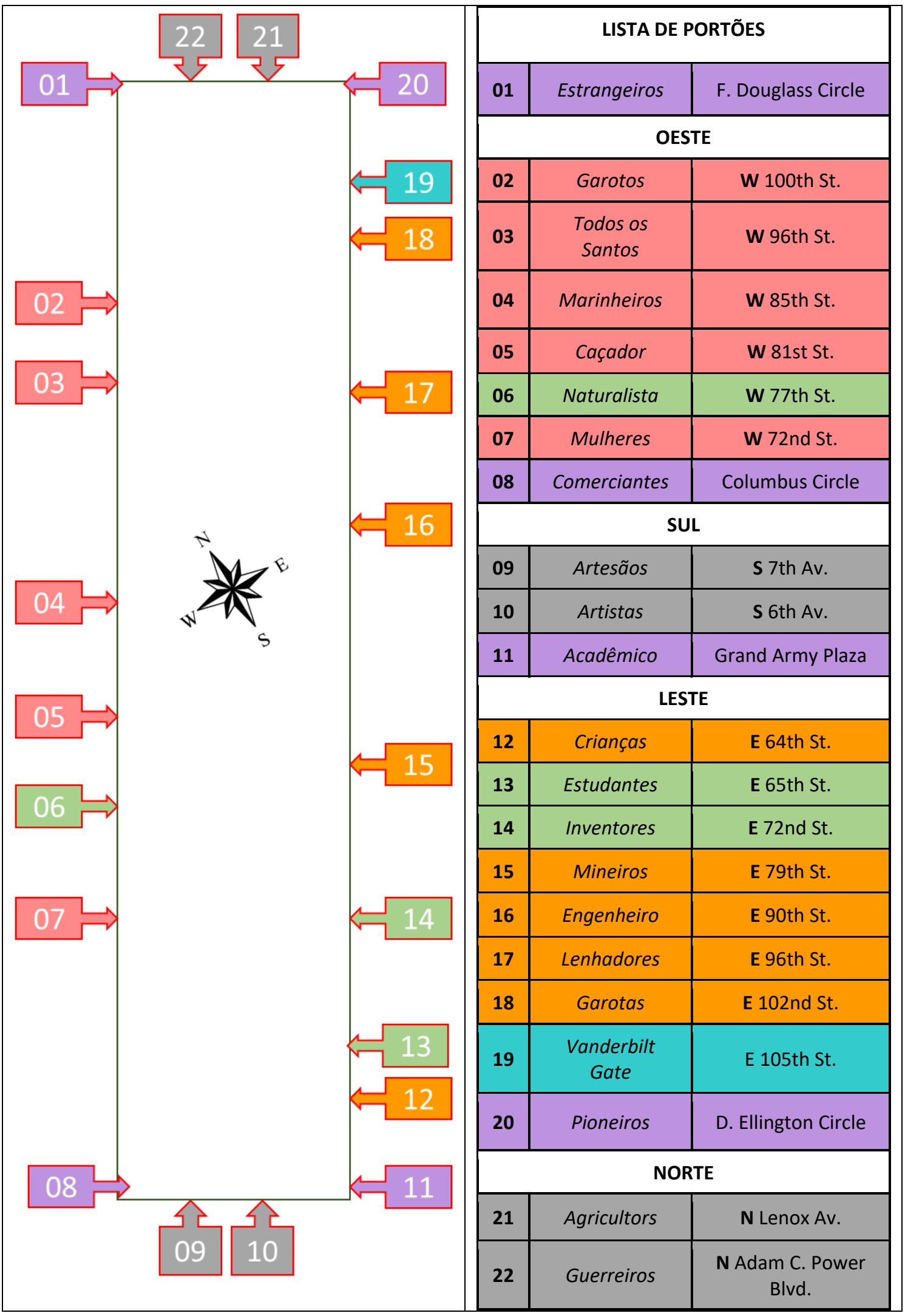

Fonte: $\mathrm{O}$ autor com base nas informações no site oficial do Central Park.

Apesar de toda essa discussão em relação à nomenclatura, a aposição das placas indicativas dos portões do CP não é tão antiga como se pensa. As primeiras placas alusivas aos nomes surgiram na década de 1950, durante a gestão de Robert Moses como diretor, e foram: Acadêmicos (Scholars, localizado na 59th 
St. com 5th Av. - Figura 7); Engenheiros (na 90th St. com 5th Av.); Marinheiros (85th St. com Central Park West); Inventores (72nd St. com 5th Av.); Crianças (64th St. com 5th Av.). As demais placas são ainda mais recentes; fazem parte de um projeto de revitalização do CP levado adiante pelo Conselho Administrativo no final da década de 1990.

A maior parte dos portões, apesar de nomeados, só receberam sua inscrição oficial em 1999 quando Mr. Henry J. Stern, o encarregado dos parques na época, retomou o procedimento como parte da restauração do parque. A última inscrição ficou pronta em dezembro de 1999 (POLLACK, 2014, s/p) ${ }^{9}$.

Figura 7: Placa do Portão do Acadêmico no CP, gravada em arenito.

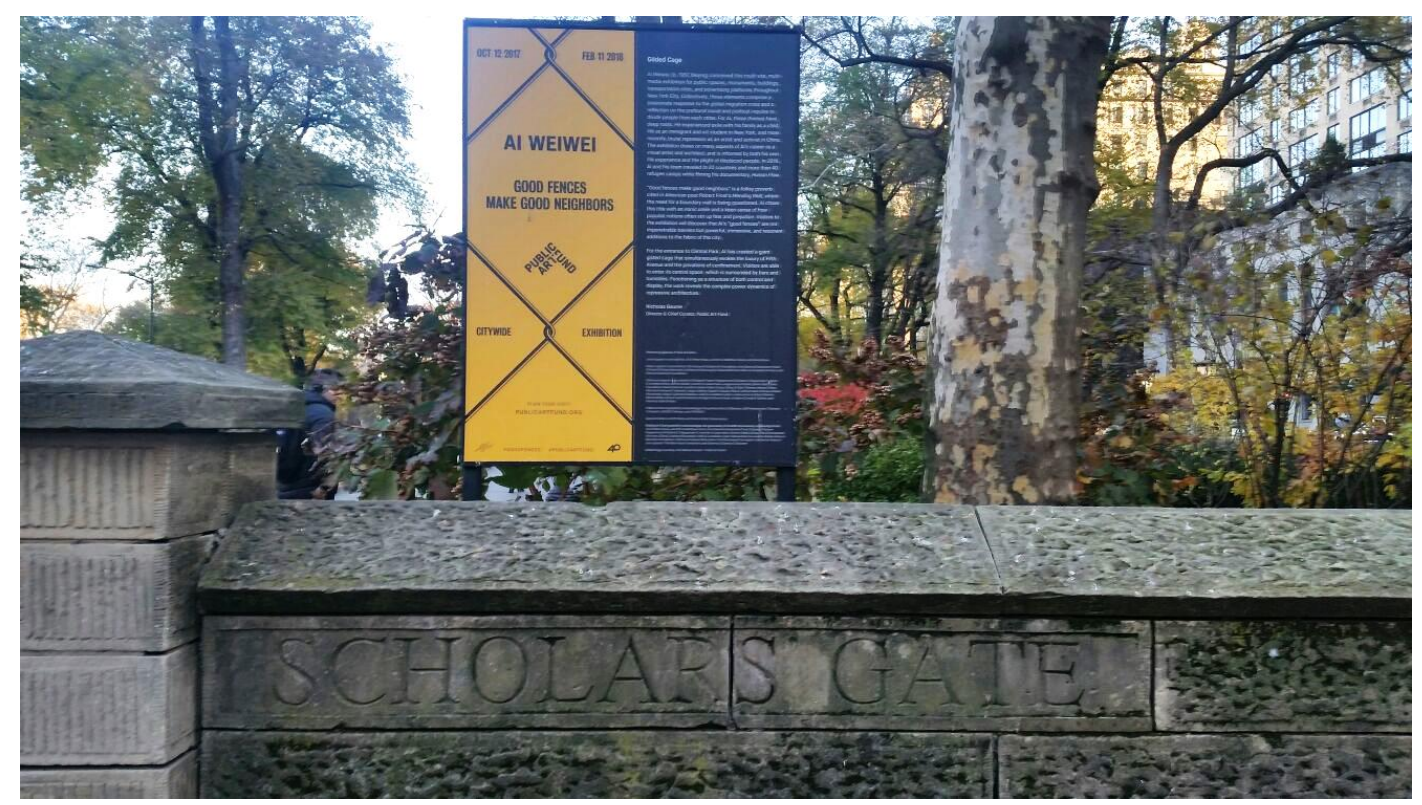

Fonte: Foto cedida por Indra Rodies (2017).

\section{CONSIDERAÇÕES FINAIS}

Na segunda metade do século XIX, no seio da principal cidade estadunidense, onde o capitalismo instalavase vorazmente, consolidou-se uma proposta urbana concebida e planejada a partir de uma base socialista, voltada para o encontro de diferentes camadas sociais, e cujos portões de contato com a cidade receberam nomes que homenageavam grupos populares que habitavam a região e participaram, direta ou indiretamente da consolidação do empreendimento. Um feito surpreendente, considerando-se o local e o período em que aconteceu. O parque tornou-se ícone urbano, parte essencial a imagem da cidade, e continua surpreendendo, não apenas por sua dimensão e pujança, mas por ter se mantido praticamente intacto enquanto a cidade fervilha ao seu redor.

Nesse contexto, seu criador passa quase desapercebido. De fato, o único portão que relaciona a existência do $\mathrm{CP}$ à Frederick Law Olmsted é o Portão Vandervilt que serve de marco para o almoço anual comemorativo à extensa obra do paisagista, que é realizado pelo Comitê Feminino do Conservatory. $O$ mesmo local também serve de melancólico marco do fim da Gilded Age (Anos Dourados) em Nova lorque e da Era Vitoriana nos Estados Unidos (CRAIN, 2017). De todos os poderosos magnatas da Era Dourada, apenas Cornelius Vanderbilt se relacionava com Olmsted, de quem fora vizinho na Staten Island, e a quem procurou para a construção dos gigantescos jardins de Biltmore.

$\mathrm{Na}$ contramão do uso democrático do espaço e contraditoriamente com relação àquela proposição inicial, hoje verifica-se a privatização de algumas instalações, como o arrendamento do rinque de patinação Wollman (que acontece desde 1987) e do Carrossel (desde 2010) pelas empresas Trump, talvez se caracterizando como uma etapa de rendição da democracia ao capitalismo (FITZSIMMONS, 2016). Em contrapartida, também existe atualmente um movimento popular voltado para o boicote aos espaços arrendados pelas empresas Trump, como protesto por sua agenda política (CHANGE.ORG, 2017), um claro indicativo que o jogo de poder naquela área continua em andamento.

Retomando a metáfora utilizada no início do item 2 deste artigo, no término do romance de Laclos a pérfida e amoral personagem de Marquesa de Merteuil é vaiada no teatro como forma de desaprovação e rejeição social. O Central Park não foi vaiado, embora já tenha passado por períodos mais decadentes (como a 
década de 1970), por épocas assépticas (como os anos 1990), e por hoje enfrentar novos desafios, notadamente a pressão imobiliária da cidade mais cara do planeta. No entanto, comparando-se com a época em que foi planejado, sua área é a mesma e seus portões continuam intactos, mantendo praticamente os mesmos nomes que lhes foram historicamente incorporados; os muito muito ricos e muito muito muito influentes, por mais que tenham desejado modificar as credenciais democráticas do CP, jamais o conseguiram, apesar de todas as tentativas. Por enquanto!

\section{REFERÊNCIAS}

CHANGE.ORG. Boycott Trump in Central Park. Abril/2017. Disponível em: https://goo.gl/kn5yQU Acesso em 10/jul/2017.

CRAIN, E. A magical garden nobody knows in Central Park. Ephemeral New York (Blog associado ao Word Press). Abril/2017. Disponível em: <https://goo.gl/eDuPmP>. Acesso em 13/07/2017.

CRAIN, E. Who named the gates of Central Park? Ephemeral New York (Blog associado ao Word Press). Maio/2010. Disponível em: <https://goo.gl/eDuPmP>. Acesso em 07/07/2017.

FITZSIMMONS, D. Carousel or Donald Trump. New York Press. Fevereiro/2016. Disponível em: https://goo.gl/5FctV5. Acesso em 02/jul/2017.

GARCIA-POSADA, A. M. Cuadernos de Central Park. Tiempos, lecturas y escritos de un territorio urbano. Tese de Doutorado. Departamento de Proyectos Arquitectónicos. Escuela Técnica Superior de Arquitectura de Sevilla. Universidad de Sevilla. 2007. (http://goo.gl/Dygwli)

GREEN, A. H., RUSSELL, C. H., STEBBINS, H. G. Fifth Annual Report of The Board of Commissioners of the Central Park. Nova lorque: WM, C. Bryant \& Co Printers, 1862.

GREEN, A. H., RUSSELL, C. H., STEBBINS, H. G. Sixth Annual Report of The Board of Commissioners of the Central Park. Nova lorque: WM, C. Bryant \& Co Printers. 1863.

GREEN, A. H., RUSSELL, C. H., STEBBINS, H. G. Thirteenth Annual Report of the Commissioners of the Central Park, (New York). 1870.

GREY, A. Definitions of Crowding and the Effects of Crowding on Health: A Literature Review. (Relatório). Ministery of Social Politics. Wellington, Nova Zelandia. 2001. Disponível em: http://goo.gl/cy8iSX. Acesso em: 24, Jan, 2014.

HUNT, R. M. Designs for the Gateways of the Southern Entrances to the Central Park. Nova lorque: D. Van Nostrand. 1866.

MARTIN, J. Genius of Place. The Life of Frederick Law Olmsted. Boston: Da Capo Press. 2011.

MEDEIROS, E. M. F. Requiescat in "park": o Central Park de Novo lorque sob a ótica do cinema norte-americano. Tese de Doutorado. Programa de Pós-graduação em Arquitetura e Urbanismo (PPGAU), Universidade Federal do Rio Grande do Norte (UFRN), 2014.

MILLER, S. C. Central Park, an American Masterpiece. Nova lorque: Harry N. Abrams, Inc. 2003.

OLMSTED, F. L. Public Parks and the Enlargement of Towns. Cambridge: The Riverside Press. 1870.

OLMSTED, F. L., VAUX, C. Description of a Plan for the Improvement of the Central Park. "Greensward". Nova lorque: The Aldine Press. 1858.

POLLACK, M. What Is Jamaica, Queens, Named After? The New York Times. Julho/2014. Disponível em: https://goo.gl/H59BVj. Acesso em: 1 de julho de 2017.

SLAVICEK, L. C. New York City's Central Park (Building America: Then and Now). New York: Chelsea House Publications, 2009.

ROSENZWEIG, R. BLACKMAR, E. The Park and the People: A History of Central Park. Nova lorque: Cornell University Press, 1998.

WALDMAN, B. Then \& Now: Remnants of the Vanderbilt Mansion in New York City. Untapped Cities. Fevereiro/2012. Disponível em: https://goo.gl/wCTSw4. Acesso em: 12/julho/2017.

WARBURG REALTY. The History of the Vanderbilt Gate. Agosto/2016. Disponível em: https://goo.gl/dEApVp. Acesso em: 12/julho/2017. 


\section{NOTAS}

1 Tradução livre do autor do original em língua inglesa. "Central Park thus emerged out of a complex mix of motivations - to make money, to display the city's cultivation, to lift up the poor, to refine the rich, to advance commercial interests, to retard commercial development, to improve public health, to curry political favor, to provide jobs" (ROSENZWEIG, BLACKMAR, 1992).

${ }^{2}$ James J. Frawley foi membro do Tammany Hall uma organização política do Partido Democrata o qual, na época, esteve fortemente associado à suborno e corrupção política particularmente na gestão das coisas públicas, e implicando diretamente o CP.

${ }^{3}$ Richard Morris Hunt, arquiteto e escultor norte-americano, foi autor do pedestal da Estátua da Liberdade, do Grande Salão do MET, além de construir muitas mansões da Quinta Avenida. Foi o criador do American Institute of Architects, o equivalente ao IAB brasileiro.

${ }^{4}$ Calvert Vaux, arquiteto e paisagista anglo-americano, parceiro de Olmsted na criação do CP.

${ }^{5}$ Andrew Haswell Green, advogado, planejador urbano e líder cívico, considerado Pai da Grande Nova lorque, foi o responsável por diversos empreendimentos dentre os quais o Central Park, o qual defendeu contra os interesses persecutórios do Tammany Hall.

${ }^{6}$ Tradução livre do autor do original em língua inglesa. "We have, first, that portion of the population whose sphere of usefulness is manual labor. This large and important class contributes to the prosperity of the community all the hard, positive, tangible work that is done, and it deserves, on entering the Park, a hearty and respectful recognition. It should scarcely be distinguished, however, by such terms as 'laborer' or 'mechanic', for every laborer may bring some skill and wit to his work, and every mechanic may show some degree of taste and cleverness in the exercise of his craft: the word 'Artizan', on the other hand, seems to present the whole idea in its more comprehensive and desirable aspect, and is, perhaps, the most characteristic title that can be used" (GREEN, 1862, p. 128-29).

${ }^{7}$ Tradução livre do autor do original em língua inglesa. "Not only was Moses to be appointed parks commissioner of the entire city, not only was that office to be expanded to include power over parkways, not only was Moses to receive control of two 'authorities' with power to build local bridges and roads (The Triborough Bridge Authority and the Marine Park Authority), but also he would be permitted to retain his four different state jobs concerned with parks and roads." (ROSENZWEIG, BLACKMAR, 1998, p. 448).

${ }^{8}$ Tradução livre do autor do original em língua inglesa. "The city, although metropolitan by position, is cosmopolitan in its associations and sympathies, and is ever ready to extend a courteous welcome to all peaceably disposed "Strangers" or "Foreigners" who may be led by inclination or business to spend their time within its boundaries; this welcome being offered, however, not merely a matter or courtesy but as a recognition of that fact that it is highly important, both to the general and particular interests of the whole nation, that its cities should be visited, and its institutions studied and comprehended by intelligent and industrious travelers from other countries, for by such means only can unworthy prejudices be removed, and incorrect estimates rectified" (OLMSTEAD, 1866, apud CRAIN, 2010, $\mathrm{s} / \mathrm{p})$ :

9 Tradução livre do autor do original em língua inglesa. "Most of the gates, though named, did not receive their official lettering until 1999, when Henry J. Stern, then the parks commissioner, resumed the practice as part of the park's restoration. The last inscription was finished in December 1999" (POLLACK, 2014, s/p).

NOTA DO EDITOR (*) O conteúdo do artigo e as imagens nele publicadas são de responsabilidade do(s) autor(es). 